(с) Коллектив авторов, 2021

Богданова И.М., Артемьева К.А., Болтовская М.Н.

\section{Развитие и функция регуляторных В-клеток и их роль в поддержании беременности}

Федеральное государственное бюджетное научное учреждение «Научно-исследовательский институт морфологии человека имени академика А.П. Авцына» Министерства науки и высшего образования Российской Федерации, 117418, г. Москва, Российская Федерация

\section{Резюме}

Традиционно функцию В-клеток преимущественно ассоциируют с гуморальным иммунитетом и положительной регуляцией иммунного ответа через продукцию специфических антител и оптимальную активацию $\mathrm{CD}^{+}-\mathrm{T}$-клеток. Однако недавно был выявлен уникальный подкласс В-клеток, позже описанный как регуляторные В-клетки (Врег). Эти клетки способны подавлять функции других иммунных клеток, включая дендритные клетки (ДК) и Т-лимфоциты, через продукцию противовоспалительных цитокинов, преимущественно интерлейкина(ИЛ)-10, который эффективно ингибирует пролиферацию и выработку провоспалительных цитокинов Т-клетками и индуцирует дифференцировку регуляторных Т-клеток (Трег). Иммуносупрессорные Врег, продуцирующие ИЛ-10, участвуют в поддержании гомеостаза в иммунной системе и толерантности к собственным антигенам. Получены данные, демонстрирующие протективную роль Врег в завершении воспаления, а также их патогенную роль через выработку аутоантител. В популяцию Врег входит уникальный функционально определенный подкласс, который в настоящее время может быть детектирован только по способности продуцировать и секретировать ИЛ-10 после соответствующей стимуляции ex vivo. В настоящее время накоплены доказательства, подтверждающие важную роль Врег в аутоиммунных и инфекционных заболеваниях, а также в формировании трансплантационной толерантности и в развитии опухолей. Врег также вовлечены в процесс становления селективной иммунной толерантности в течение беременности, необходимой для обеспечения иммунопривилегированного микроокружения полуаллогенного плода. Показано, что нарушение численности и функциональной активности Врег может приводить к развитию различных иммуноопосредуемых патологий беременности, таких как повторные неудачи имплантации, привычное невынашивание беременности и преждевременные роды. В обзоре представлены результаты исследований, посвященных изучению биологии и функциональной роли Врег в регуляции процессов репродукции.

Ключевые слова: регуляторные В-клетки; иммунорегуляция; беременность; иммунная толерантность; интерлейкин-10

Статья получена 02.04.2021. Принята в печать 16.06 .2021

Для цитирования: Богданова И.М., Артемьева К.А., Болтовская М.Н. Развитие и функция регуляторных В-клеток и их роль в поддержании беременности. Иммунология. 2021; 42 (4): 415-425. DOI: https://doi. org/10.33029/0206-4952-2021-42-4-415-425

Финансирование. Работа выполнена в рамках государственного задания ФГБНУ «Научно-исследовательский институт морфологии человека» (№ АААА-А17-117013050049-3).

Конфликт интересов. Авторы заявляют об отсутствии конфликта интересов
Для корреспонденции Богданова Ирина Марковна кандидат биологических наук, старший научный сотрудник лаборатории патологии репродукции ФГБНУ НИИМЧ им. ак. А.П. Авцына Минобрнауки России, Москва, Российская Федерация E-mail:malaj43@mail.ru http://orcid.org/0000-0002-6529-8149

Bogdanova I.M., Artemyeva K.A., Boltovskaya M.N.

\title{
Development and function of regulatory $B$ cells and its role in pregnancy support
}

A.P. Avtsyn Research Institute of Human Morphology, Ministry of Science and High Education of the Russian Federation, 117418, Moscow, Russian Federation 


\section{Abstract}

Traditionally, B cell function is predominantly associated with humoral immunity and positive regulation of the immune response through the production of specific antibodies and optimal activation of $\mathrm{CD}^{+}-\mathrm{T}$ cells. However, a unique subclass of $\mathrm{B}$ cells has recently been identified, later described as regulatory B cells (B-regulatory, Breg). These cells are capable of suppressing the functions of other immune cells, including dendritic cells (DC) and T-lymphocytes, through the production of anti-inflammatory cytokines, predominantly interleukin(IL)-10, which effectively inhibits the proliferation and production of pro-inflammatory cytokines by $\mathrm{T}$ cells and induces the differentiation of regulatory $\mathrm{T}$ cells (T-regulatory, Treg cells). Immunosuppressive Bregs that produce IL-10 are involved in maintaining homeostasis in the immune system and self-antigen tolerance. The data obtained confirming the protective role of Bregs in the completion of inflammation, as well as their pathogenic role through the production of autoantibodies. The Breg population includes a unique functionally defined subclass that can currently only be detected by its ability to produce and secrete IL-10 following appropriate ex vivo stimulation. Evidence is now accumulating to support an important role for Bregs in autoimmune and infectious diseases, as well as in the formation of graft tolerance and tumor development. Breg are also involved in the formation of selective immune tolerance during pregnancy, which is necessary to ensure the immuno-privileged microenvironment of the semi-allogeneic fetus. It has been shown that a violation of the number and functional activity of Breg can lead to the development of various immunologically mediated pathologies of pregnancy, such as recurrent implantation failure, recurrent pregnancy loss and premature birth. This review presents the results of studies on the biology and functional role of Breg in the regulation of reproductive processes.

Keywords: regulatory B cell; immunoregulation; pregnancy; immune tolerance; interleukin-10

Received 02.04.2021. Accepted 16.06.2021.

For citation: Bogdanova I.M., Artemyeva K.A., Boltovskaya M.N. Development and function of regulatory B cells and its role in pregnancy support. Immunologiya. 2021; 42 (4): 415-25. DOI: https://doi.org/10.33029/0206-49522021-42-4-415-425 (in Russian)

Funding. The work is done in the framework of the state assignment of Research Institute of Human Morphology (No AAAA-A17-117013050049-3).

Conflict of interests. The authors declare no conflict of interests.

\section{Введение}

Традиционно считается, что к основным функциям В-клеток в составе гуморального звена иммунитета относятся распознавание антигенных детерминант чужеродных патогенных микроорганизмов, развитие антиген-специфического иммунного ответа через выработку антител и дифференцировка в клетки памяти, обеспечивающие длительно сохраняющийся иммунитет. В силу этого В-клетки было принято считать положительными регуляторами гуморального иммунного ответа. В последние годы были открыты дополнительные функции В-клеток, включая презентацию антигена, секрецию цитокинов и способность ингибировать иммунный ответ $[1,2]$. Популяция В-лимфоцитов содержит множество подклассов с различными функциональными свойствами [3]. В-клетки могут играть патогенную роль в аутоиммунных заболеваниях человека через продукцию аутоантител и формирование иммунных комплексов, которые индуцируют локальные воспалительные реакции и деструктивные изменения в тканях [4]. Определенные подклассы В-клеток подавляют иммунное воспаление у мышей, а их дефицит приводит к обо- стрению аутоиммунного заболевания $[5,6]$. Выявлен подкласс супрессорных В-лимфоцитов, известных под общим названием регуляторные В-клетки (Врег), обладающие способностью негативно регулировать другие типы иммунных клеток [7]. По данным многочисленных исследований в области аутоиммунитета, трансплантационной толерантности и онкологии, Врег способны мощно модулировать иммунный ответ, подавляя избыточную воспалительную реакцию. Врег оказывают влияние на иммунную систему через продукцию цитокинов или межклеточные взаимодействия. Цитокины в первую очередь регулируют развитие местных защитных реакций путем формирования типичной воспалительной реакции, а также модулируют направленность дифференцировки Тh0-лимфоцитов [8, 9]. Ключевым цитокином Врег является противоспалительный цитокин ИЛ-10, который ингибирует выработку провоспалительных цитокинов и поддерживает дифференцировку Трег. Иммуносупрессорные Врег, экспрессирующие ИЛ-10, вовлечены в поддержание гомеостаза в иммунной системе и индукцию толерантности к собственным антигенам [10]. 
Впервые супрессорная функция В-клеток была отмечена в работах 1970-х гг. с использованием модели контактной гиперчувствительности замедленного типа (ГЗТ) у морских свинок, в которой Т-клетки индуцируют локальный воспалительный ответ на повторный контакт с иммуногеном. Авторы наблюдали повышение тяжести и продолжительности реакции ГЗТ после избирательного удаления В-клеток и пришли к выводу, что В-клетки способны ингибировать функцию Т-клеток $[11,12]$. Однако механизмы, ответственные за супрессию, не были охарактеризованы, и изучение супрессорных В-клеток временно прекратилось. Исследования по В-клеточной супрессии возобновились благодаря наблюдению, согласно которому у генетически модифицированных мышей с дефицитом В-клеток, в отличие от мышей дикого типа, не происходит восстановление от экспериментального аутоиммунного энцефаломиелита (ЭАЭ) [13]. Адоптивный перенос В-клеток селезенки от мышей дикого типа подавлял опосредуемое Т-клетками аутоиммунное воспаление [14]. Другие авторы показали, что В-клетки ингибируют иммунное воспаление, вырабатывая противовоспалительный цитокин ИЛ-10 на моделях хронического колита [15], ЭАЭ [6] и артрита [16].

Таким образом, Врег были определены как важные участники процесса формирования и поддержания иммунной толерантности, способные негативно регулировать другие типы иммунных клеток, включая дендритные клетки (ДК) и Т-лимфоциты и, несмотря на их небольшое количество, мощно модулировать иммунный ответ [10, 17].

В контексте беременности знания о природе и механизмах действия Врег остаются ограниченными. Их важное значение подтверждено результатами исследований, в которых показано, что Врег способны подавлять воспалительные реакции, а также индуцировать и поддерживать иммунную толерантность матери к полуаллогенному плоду [18-20]. Также адоптивный перенос Врег способствует восстановлению фетальной толерантности у мышей с иммуноопосредуемыми осложнениями беременности. Кроме того, установлена корреляция между дефицитом Врег и неблагоприятным исходом беременности, таким как привычные до- и постимплантационные потери беременности [21, 22].

Настоящий обзор посвящен анализу современных знаний о биологии Врег и их вкладу в поддержание успешной беременности. Описаны фенотипические и функциональные характеристики Врег, механизмы их супрессорного действия. Представлены доказательства, подтверждающие ключевую роль противовоспалительного цитокина ИЛ-10, продуцируемого Врег, в подавлении ответа в сайтах иммунной активации и воспаления. Показано участие Врег в создании толерантного микроокружения в маточно-плацентарной области, необходимого для успешного развития полуаллогенного плода, а также в развитии осложнений беременности при нарушениях, связанных с дефицитом числа и/или функциональной активности Врег.

\section{Происхождение и фенотипическая характеристика регуляторных В-клеток}

Стадии развития В-клеток включают пре-В-клетки, незрелые В-клетки, зрелые В-клетки, активированные В-клетки и плазматические клетки. В костном мозге развитие пре-В-клеток и незрелых В-клеток происходит по антиген-независимому механизму, в то время как дифференцировка зрелых В-клеток, активированных В-клеток и плазматических клеток является антиген-зависимой и происходит в периферических лимфоидных органах. На основе экспрессии поверхностных маркеров были идентифицированы В1- и В2-субпопуляции В-клеток. Далее в популяции В-клеток были идентифицированы фолликулярные В-клетки, присутствующие в лимфоидных фолликулах вторичных лимфоидных органов и в периферической крови, и В-клетки, локализующиеся преимущественно в маргинальной зоне селезенки (MZB-клетки). При активации фолликулярные и MZB-клетки терминально дифференцируются в плазматические клетки. IgM-клетки памяти человека, которые экспрессируют поверхностный IgM и CD27, относят к аналогу MZB-клеток мыши. Врег представлены в В1- и В2-субпопуляциях [23].

Одна из основных характеристик Врег - высокая степень гетерогенности. Выявлено множество подклассов В-клеток с функцией негативных регуляторов иммунного ответа, что в значительной степени затрудняет их фенотипическую идентификацию.

В-клетки, активно продуцирующие ИЛ-10 (В10клетки), трудно идентифицировать in vitro вследствие их очень малого количества. Однако В10, функционально запрограммированные на продукцию ИЛ-10 in vivo, могут быть идентифицированы ex vivo после 5-часовой стимуляции очищенной популяции В-клеток с использованием активатора протеинкиназы С форбол-12миристат-13-ацетата (ФМА) и кальциевого ионофора иономицина вместе с монензином (ФИМ) или брефелдином (ФИБ), блокирующим секрецию белка у мышей или у человека соответственно. Это приводит к накоплению цитоплазматического ИЛ-10 на уровне, достаточном для обнаружения ИЛ-10 компетентных В-клеток с помощью иммунофлуоресцентного окрашивания. Добавление липополисахарида (ЛПС) в систему ФИМ стимуляции увеличивает продукцию ИЛ-10. Большинство В-клеток не экспрессирует ИЛ-10 даже после длительной стимуляции ФИМ или ФИБ, т.е. не являются ИЛ-10-компетентными. Специфический фактор транскрипции, подобный Foxp3 для Трег, или клеточный поверхностный маркер, уникальный для В10-клеток, не были идентифицированы. Фенотип В10-клеток может быть определен ex vivo при кратковременной стимуляции ЛПС и ФМА, значительно не меняющей экспрессию большинства поверхностных белков клетки. В среднем частота выявляемых В10-клеток составляет $0,8 \%$ общей популяции В-клеток в периферической крови человека [24]. У мышей В10-клетки составляют 1-3 \% популяции В-клеток селезенки, и их количество 


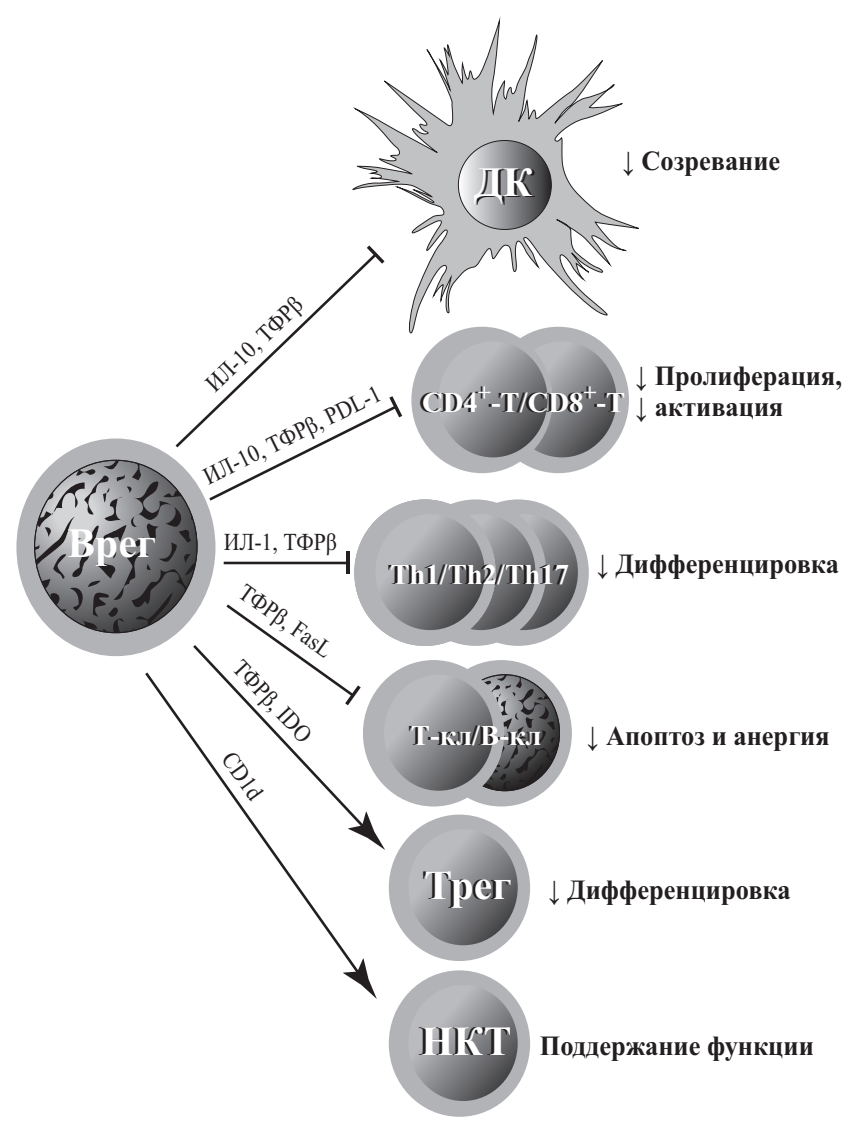

Рис. 1. Механизмы модуляции иммунного ответа В-регуляторными клетками

Здесь и на рис. 2: ИЛ-1 - интерлейкин-1; Ил-10 - интерлейкин-10; ТФР $\beta$ - трансформирующиий фактор роста $\beta$; PDL-1 лиганд PD-1; FasL - Fas-лиганд; IDO - индоламин 2,3-диоксигеназа; ДК - дендритная клетка; $C D 4^{+}-T / C D 8^{+}-T-$ CD4+-T-клетки/CD8+-T-клетки; Th1/Th2/Th17 - Th1-, Th2-, Th17-лимфоциты; $T$-кл/В-кл - Т-клетки/В-клетки; Трег - регуляторная Т-клетка; НКТ - НКТ-клетка.

значительно возрастает в условиях воспаления [25]. В настоящее время с использованием различных экспериментальных моделей идентифицировано множество подклассов Врег с перекрывающимися фенотипическими и функциональными характеристиками. У мышей описаны подклассы ИЛ-10-продуцирующих В-клеток, которые включают MZ-предшественники переходной стадии 2 (T2-MZP клетки), $\mathrm{CD}^{+} \mathrm{CD}^{+} \mathrm{d}^{+}$-В-клетки (B10), MZB-клетки, TIM1+-B-клетки, CD138+-плазматические клетки и плазмабласты. У человека идентифицированы $\mathrm{CD} 19^{+} \mathrm{CD} 24^{\text {high }} \mathrm{CD} 38^{\text {high }} \mathrm{CD} 1 \mathrm{~d}^{\text {high }}$ - и $\mathrm{CD} 19^{+} \mathrm{CD} 24^{+} \mathrm{CD} 27^{+}-$ Врег [26, 27]. Гетерогенность этих подклассов дает основания полагать, что Врег не являются потомками одной общей специфической линии, а могут генерироваться от различных подклассов В-клеток. По данным литературы, их происхождение зависит не только от принадлежности к определенному подклассу, но и от других факторов, таких как статус активации В-клеток и их специфическое микроокружение. Окончательный ответ на вопрос о происхождении Врег еще не получен и требует дальнейшего уточнения [28].
Как и в экспериментальных моделях на мышах, Врег человека преимущественно идентифицировали на основании способности продуцировать ИЛ-10 [10, 29]. Трудности идентификации Врег привели к использованию суррогатных маркеров, которые включают $\mathrm{CD}^{+} \mathrm{CD} 1 \mathrm{~d}^{+}$для ИЛ-10-продуцирующих $\mathrm{B}$-клеток (B10-клетки) у мышей и $\mathrm{CD} 24^{\text {high }} \mathrm{CD} 27^{+}-$у человека. Многочисленные подклассы ИЛ-10+-В-клеток широко представлены во многих периферических тканях. У человека они выявлены в селезенке, миндалинах, пуповинной крови новорожденных, где они составляют 0,3-0,8 \% общей популяции В-клеток и их количество с возрастом снижается. Таким образом, В10-клетки входят в состав многих фенотипически определяемых субпопуляций, демонстрируя, что на данный момент ИЛ-10-компетентность остается лучшим фенотипическим маркером для идентификации этого специфического подкласса В-клеток [24].

\section{Механизмы, контролирующие супрессорную функцию регуляторных В-клеток}

Как было показано, Врег, идентифицированные у мышей и у человека, способны подавлять воспаление и отрицательно регулировать иммунный ответ (рис. 1).

Механизмы, ответственные за функциональную активность Врег, включают секрецию ингибиторных медиаторов и межклеточные контакты, опосредуемые поверхностными молекулами В-клеток. Важную роль в повышении экспрессии ИЛ-10 и усилении супрессорной функции Врег играют факторы микроокружения, к которым относится большинство воспалительных цитокинов [30].

Наиболее полно изученный механизм негативной регуляции Врег - их способность продуцировать противовоспалительные цитокины, главным образом ИЛ-10. Ключевые функции ИЛ-10 - подавление избыточного воспалительного ответа и поддержание иммунного гомеостаза через многочисленные механизмы, такие как ингибирование антигенной презентации, снижение уровня экспрессии костимуляторных молекул CD80, CD86 и молекул MHC класса II на макрофагах и ДК, а также ограничение продукции цитокинов Т-клетками и усиление дифференцировки Трег [31]. У здоровых индивидов $\mathrm{CD} 19^{+} \mathrm{CD} 24^{\text {high }} \mathrm{CD} 38^{\text {high }}$-В-клетки ингиби-

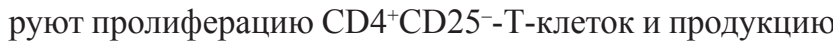
интерферона(ИФН)- $\gamma$ и фактора некроза опухоли(ФНО) $\alpha$ этими клетками, а также подавляют дифференцировку наивных Т-лимфоцитов в Th1- и Th17-эффекторные клетки и способствуют созреванию $\mathrm{CD} 4{ }^{+} \mathrm{CD} 25^{-}-\mathrm{T}$ клеток в Трег через продукцию ИЛ-10 [27, 32].

В то время как секреция ИЛ-10 определяет главную негативную регуляторную функцию Врег, существуют другие независимые от ИЛ-10 супрессорные механизмы, которые включают продукцию трансформирующего фактора роста(ТФР) $\beta$, ИЛ-35 и ИЛ-17. ТФР $\beta$, продуцируемый В-клетками, усиливает дифференцировку и поддержание $\mathrm{CD}^{+} \mathrm{FoxP} 3^{+}-$ Трег при диабете, трансплантации, аллергических заболеваниях и колите [33]. Через продукцию ТФР $\beta$ 
В-клетки, активированные ЛПС, могут индуцировать апоптоз $\mathrm{CD}^{+}-$[34] и анергию эффекторных CD8 ${ }^{+}$-Т-клеток [35].

ИЛ-35, экспрессируемый В-клетками, - важный участник негативной регуляции иммунного ответа. Иммуносупрессорный гетеродимерный цитокин ИЛ-35, связываясь с соответствующим рецептором, активирует факторы транскрипции STAT1 и STAT3, индуцирует дифференцировку покоящихся В-клеток в ИЛ-10и ИЛ-35-продуцирующие Врег [36]. ДК с индуцированной продукцией ИЛ-35 и фосфорилированием STAT3 способны стимулировать иммуносупрессорную функцию В10-клеток [37]. Мыши с дефицитом В-клеток, экспрессирующих ИЛ-35, теряют способность восстанавливаться от опосредуемого Т-клетками ЭАЭ. У таких мышей зарегистрирован более высокий уровень $\mathrm{CD}^{+}$-Т-клеток и мононуклеарных фагоцитов в центральной нервной системе. В популяции В-клеток селезенки повышена экспрессия маркеров активации (CD44, CD69) и молекул, вовлеченных в презентацию антигена CD4+-T-клеткам (CD80, CD86, MHC-II) при сравнении с мышами дикого типа. В то же время эти животные значительно более устойчивы к инфицированию внутриклеточным бактериальным патогеном Salmonella enterica, о чем свидетельствуют их высокая способность к сдерживанию роста бактерий и их длительная выживаемость после инфицирования. Повышенный уровень иммунитета, обнаруженный у мышей, лишенных продукции ИЛ-35 В-клетками, связан с усилением активации макрофагов и воспалительных Т-лимфоцитов, ДК, Th17- и Th1-клеток и цитотоксичес-

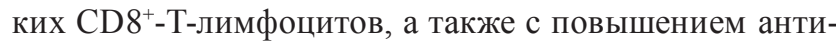
ген-представляющей функции В-клеток [38-40].

Подобно ИЛ-35, ИЛ-21 тоже индуцирует продукцию ИЛ-10 Врег через фосфорилирование STAT3. Ингибирование фосфорилирования STAT3 эффективно блокирует продукцию ИЛ-10 в течение дифференцировки Врег. Влияние ИЛ-21 на дифференцировку Врег строго зависит от дополнительных сигналов, включая агонисты Toll-подобных рецепторов (Toll-like receptor, TLR), a также стимуляцию В-клеточного рецептора (BCR) для антигена и CD40. На модели рассеянного склероза у мышей показали, что созревание В-клеток в функциональные ИЛ-10-секретирующие эффекторные Врег требует ИЛ-21- и CD40-зависимых взаимодействий с Т-клетками [41].

Секреция ИЛ-17 активированными В-клетками играет важную роль в контроле и разрешении воспаления при некоторых паразитарных инфекциях. Показано, что транс-сиалидаза - фермент, представленный на поверхности протозойного паразита Tripanosoma cruzi, индуцирует продукцию ИЛ-17 при контакте с В-клетками [42].

Врег могут оказывать регуляторное действие на клетки-мишени, используя ферменты, такие как гранзим В и индоламин-2,3-диоксигеназа (ИДО). Активированные В-клетки регулируют пролиферацию Т-клеток и их дифференцировку в Трег через продукцию ТФР $\beta$ и ИДО. Врег, активированные в присутствии ИЛ-21 с вовлечением BCR, продуцируют гранзим В - проапоптотическую сериновую протеазу, которая, проникая в цитоплазму, может привести к апоптотической гибели аутореактивных В-лимфоцитов и других иммунных клеток [43]. Молекулы, экспрессируемые на клеточной поверхности Врег, также играют важную роль в негативной регуляции иммунитета, осуществляемой при тесном взаимодействии с воспалительными эффекторными Т-клетками [36]. Эти молекулы на поверхности Врег могут подавлять функцию иммунных клеток, способствовать дифференцировке Трег и апоптозу клеток-мишеней. К ним относятся CD80, CD86 - лиганд рецептора программируемой клеточной гибели 1 (PD-L1), CD40L, CD1d и Fas-лиганд (FasL). Эти молекулы, экспрессируемые Врег, опосредуют их супрессорную функцию через прямые межклеточные взаимодействия.

CD80- и CD86-молекулы B7-семейства, экспрессируемые на антиген-представляющих клетках, играют важную роль в создании иммунных синапсов и активации адаптивного иммунного ответа. Хотя ИЛ-10 является ключевым цитокином, необходимым для супрессии, вовлечение костимуляторных молекул CD80 и CD86, экспрессируемых Врег, усиливает ИЛ-10индуцируемое подавление Th1-ответа [27]. Повышение экспрессии PD-L1 на B-клетках приводит к угнетению

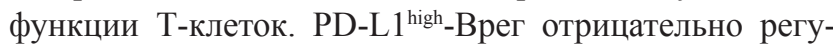
лируют дифференцировку Т-клеток путем связывания c PD-1. Адоптивный перенос PD-L1-B-клеток защищает животных от ЭАЭ и снижает тяжесть заболевания через подавление активности воспалительных Т-клеток и индукцию Трег $[44,45]$.

Подобным образом, В-клетки, экспрессирующие FasL, предотвращают отторжение аллогенного трансплантата у мышей и модулируют индукцию аутоиммунного процесса при коллаген-индуцированном артрите с использованием нескольких механизмов, включая усиление апоптоза аутореактивных Т-клеток и генерирование Трег [46]. МНС класс І-подобная молекула CD1d, ответственная за представление липидных антигенов естественным киллерным Т-клеткам (НКТ), является главным фенотипическим маркером, высокоэкспрессированным на многих Врег. Как полагают, CD1d играет важную роль в Врег-опосредуемой супрессии. Повышение экспрессии CD1d на В-клетках связано с усилением их протективной функции при воспалительных заболеваниях кишечника у мышей $[5,47]$, а также участвует в поддержании и активации НКТ-клеток [26].

Разнообразие функциональных механизмов Врег может быть связано с различными сигналами, воспринимаемыми В-клетками в течение иммунного ответа. Вполне вероятно, что различные механизмы, используемые Врег, могут действовать одновременно, взаимодействуя друг с другом для усиления эффективности подавления иммунного ответа. 


\section{Активация регуляторных В-клеток}

Развитие, созревание и/или экспансия В10-клеток контролируются на молекулярном уровне. На генерирование В10-клеток in vivo и in vitro влияют факторы, ассоциированные как с адаптивным, так и с врожденным иммунитетом [48]. Сигнальные молекулы, включая поверхностные белки, такие как TLRs, костимуляторные молекулы CD40, CD80/86 или фактор активации B-клеток (BAFF), BCR, CD19, TIM1, MHCIIb, CD62L, цитокины - ИЛ-1 $\beta$, ИЛ-6, ИЛ-21, ИЛ-35 и ИФН типа I участвуют в индукции супрессорной функции В-клеток [49]. Дифференцировка и созревание В10-клеток селезенки требует специфических внешних сигналов. Связывание ЛПС с TLR2/4 и ДНК-комплекса с TLR9 может индуцировать продукцию ИЛ-10-подобных эффекторных цитокинов Врег, повышая эффективность передачи BCR-сигнала через Myd88-сигнальный путь [50]. В10клетки функционируют по антиген-зависимому механизму, т.е. развитие и эффекторная функция В10-клеток контролируются in vivo BCR различной специфичности, преимущественно BCR зародышевой линии, включая те, которые обладают реактивностью в отношении аутоантигенов [51, 52]. Наряду с активацией сигнального пути через BCR для генерирования B10-клеток важны поликлональные сигналы, такие как CD40 и ЛПС, которые могут индуцировать их созревание и/или регуляторную функцию [48]. В-клеточная активация контролируется четырьмя классами рецепторов, а именно $\mathrm{BCR}$, цитокиновыми рецепторами, рецепторами, участвующими в тесном T-В-клеточном взаимодействии и рецепторами врожденного иммунитета, включая TLRs $[29,49]$.

В экспериментальной модели аутоиммунного воспаления показано, что при адоптивном переносе В10клетки от мышей, примированных специфическим антигеном, более эффективны в излечении заболевания, чем В10-клетки от интактных мышей. На модели ЭАЭ показано, что восстановление от болезни зависит от присутствия аутоантиген-реактивных В-клеток [6]. У гуманизированных CD19 трансгенных мышей, ха-

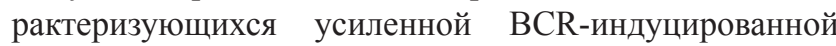
сигнальной функцией, повышено количество В10клеток, в то время как у CD19-дефицитных животных c нарушенным механизмом передачи сигнала через BCR B10-клетки представлены в незначительном количестве или вовсе отсутствуют. В10-клетки селезенки и перитонеальной полости используют разнообразный репертуар BCR-генов, преимущественно зародышевой линии, т. е. В10-клетки генерируются в ответ на ряд антигенов в отсутствие соматической гипермутации и созревания аффинности BCR в зародышевых центрах. У многих линий трансгенных мышей с фиксированным BCR-репертуаром количество В10-клеток в селезенке на 90 \% ниже, чем у мышей дикого типа [48].

В10-клетки не только участвуют в регуляции воспалительного иммунного ответа через продукцию ИЛ-10, но также способны дифференцироваться в антителопродуцирующие плазматические клетки in vivo и in vitro после кратковременного периода продукции ИЛ-10. В10-клетки продуцируют антиген-специфические антитела и представляют собой значимый источник полиреактивных и аутореактивных сывороточных IgM- и IgG-антител с различной специфичностью благодаря большому разнообразию экспрессируемых ими BCR. По-видимому, антиген-специфические сигналы in vivo отбирают те предшественники В10-клеток, которые развиваются в ИЛ-10-компетентные В10-клетки в ответ на контакт с антигеном и/или TLR-сигнал до начала дифференцировки в плазматические клетки. Следовательно, В-клетки в ответ на BCR-распознавание и воспаление могут дифференцироваться в регуляторные и антителопродуцирующие клетки, не только ограничивая острое воспаление благодаря кратковременной продукции ИЛ-10, но и способствуя выведению индуцирующих их антигенов через врожденную способность быстро генерировать полиреактивные и/или антиген-специфические антитела в течение гуморального иммунного ответа [53].

Таким образом, развитие и регуляторная функция В10-клеток жестко контролируется in vivo с помощью различных молекулярных механизмов для предотвращения генерализованной иммуносупрессии из-за неконтролируемой секреции ИЛ-10 [29].

\section{Регуляторные В-клетки и беременность}

Беременность у млекопитающих - уникальный, ограниченный во времени биологический процесс, требующий системной перестройки в иммунной системе матери. Иммунная адаптация к беременности предполагает установление тонкого, строго регулируемого баланса между иммунной активацией, обеспечивающей защиту матери от патогенных микроорганизмов с одной стороны и селективной толерантностью к полуаллогенному плоду с другой. Минимальные нарушения этого равновесия могут иметь нежелательные последствия как для потомства, так и для матери. Успешная беременность требует тесных взаимодействий между фетальными и материнскими клетками и тканями. Изменение иммунного профиля, необходимое для поддержания нормальной гестации, в которое вовлечены клетки врожденного и адаптивного иммунитета, включает супрессию Т-клеток-эффекторов, специфичных к чужеродным фетальным антигенам, генерирование Трег, модуляцию функции НК-клеток, макрофагов, моноцитов и ДК $[54,55]$.

В создании и поддержании иммунной толерантности к полуаллогенному плоду в маточном микроокружении определяющую роль играют 3 типа иммунных клеток: Врег, Трег и ДК. При нормально протекающей беременности большинство децидуальных ДК остаются незрелыми, приобретают толерогенный фенотип под действием ИЛ-10 и ТФР $\beta$, продуцируемых Врег, и участвуют в формировании толерогенного для плода микроокружения. Толерогенные ДК и Трег также продуцируют ИЛ-10 и ТФР $\beta$, предотвращая активацию Т-лимфоцитов и способствуя формированию материн- 
ско-фетального толерантного микроокружения. Врег также играют ключевую роль в течение беременности, особенно на начальной стадии индукции иммунной толерантности матери к полуаллогенному плоду, обеспечивая экспансию Трег через CD80/CD86-костимуляцию и продукцию ИЛ-10 и ТФР $\beta$. Таким образом, тесное взаимодействие между Врег, Трег и толерогенными ДК по принципу обратной связи необходимо для поддержания толерантного микроокружения в матке в течение беременности [56] (рис. 2).

Цитокины являются ключевыми регуляторами беременности. В течение успешной беременности воспалительная фаза, опосредуемая Th1-цитокинами - ФНО $\alpha$ и ИФН- $\gamma$, необходимая для имплантации эмбриона в стенку матки, сменяется противовоспалительным ответом через продукцию Тh2-цитокинов - ИЛ-4, ИЛ-10, ИЛ-13, необходимым для установления материнско-эмбрионального диалога, а также индукции толерантности к полуаллогенному плоду и иммунной супрессии [57].

В то время как функциональные свойства и механизм регуляторного действия Врег достаточно полно охарактеризованы и подтверждены многочисленными исследованиями в области аутоиммунитета, трансплантационной толерантности и онкологии, их роль в процессах репродукции недостаточно изучена. Лишь в последние 2 десятилетия исследования в этом направлении получили свое развитие.

В экспериментальной модели потери беременности у мышей F. Jensen и соавт. показали, что снижение частоты регуляторных В10-клеток на ранних сроках беременности ассоциировано со спонтанными абортами. Восстановление этого подкласса через пассивный перенос in vivo $\mathrm{CD} 19^{+} \mathrm{CD} 5^{+} \mathrm{CD} 1 \mathrm{~d}^{\text {high }}$-B10-клеток селезенки с высоким содержанием ИЛ-10 приводило к значительному снижению доли зрелых $\mathrm{CD} 11 \mathrm{c}^{+} \mathrm{CD} 80^{+}$-ДК в селезенке и к повышению уровня $\mathrm{CD}^{+} \mathrm{Foxp}^{+}-\mathrm{Tp} е г$ в дренирующих матку лимфоузлах. ИЛ-10, секретируемый Врег, способствовал сохранению беременности, ингибируя созревание ДК. ИЛ-10 и ТФР $\beta$, секретируемые Врег, необходимы для экспансии и индукции супрессорной активности Трег. Снижение доли зрелых $\mathrm{CD} 11 \mathrm{c}^{+} \mathrm{CD} 80^{+}-Д К$ зависит от ИЛ-10, продуцируемого B-клетками. Поддержание циркулирующих ДК в незрелом состоянии, когда они неспособны эффективно представлять антиген Т-клеткам, препятствует активации Т-клеточного ответа матери против антигенов отца. Подобным образом перенос В10-клеток, но не ИЛ-10-В-клеток, или В-клеток от ИЛ-10-дефицитных мышей, предотвращает ЛПС-индуцированные фетальные потери через угнетение выработки ИЛ-6 и ИЛ-17А Т-клетками и индукцию Трег $[18,19,58]$. Протективный эффект ИЛ-10 связан с подавлением синтеза макрофагами провоспалительных цитокинов, таких как ФНО ИЛ-1, ИЛ-6 и ИЛ-12. С использованием ИЛ-10 мутантных мышей C57BL/6 Il10 дозы ЛПС, было показано, что дефицит ИЛ-10 приводит к резорбции эмбрионов и задержке роста сохранившихся плодов. Рекомбинантный ИЛ-10 отменяет повышенную

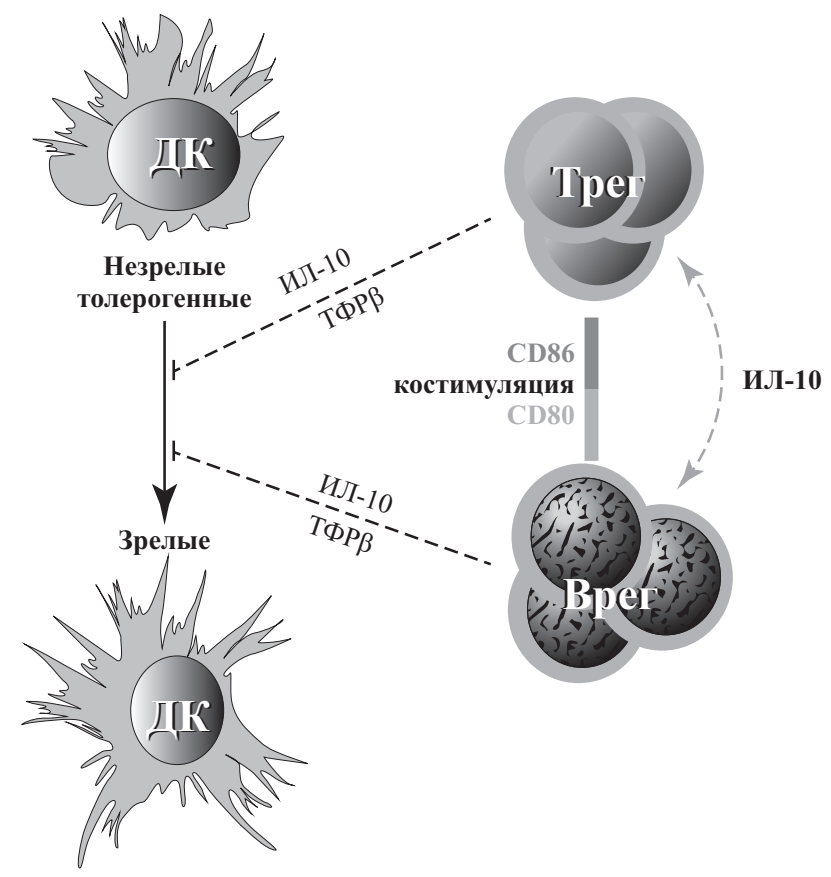

Рис. 2. Взаимодействие регуляторных В-клеток (Врег), регуляторных Т-клеток (Трег) и дендритных клеток (ДК) в течение беременности

чувствительность к ЛПС-индуцированным фетальным потерям у $I l 10^{-/-}$-мышей. Также оценивали роль ИЛ-10 в регуляции ЛПС-индуцированных преждевременных родов у мутантных $I l 10^{-/}$- и контрольных $I l 10^{+/+}$-мышей. Доза ЛПС, введенного на 17-й день гестации (ДГ), индуцирующая 50 \% потерю плодов, была в 10 раз ниже у $I l 10^{-/-}$-, чем у $I l 10^{+/+}$-мышей. Значительное повышение уровня иммуноактивных ФНО $\alpha$ и ИЛ-6 наблюдали в сыворотке, матке и плаценте $I l 10^{-/-}$-мышей. Введение $1 l 10^{-/-}$-мышам рекомбинантного ИЛ-10 приводит к снижению продукции провоспалительных цитокинов и уменьшению частоты преждевременных родов. Таким образом, ИЛ-10 модулирует резистентность к воспалительным стимулам, снижая экспрессию провоспалительных цитокинов [59, 60].

У женщин с нормально протекающей беременностью количество Врег $\left(\mathrm{CD} 19^{+} \mathrm{CD} 24^{\text {high }} \mathrm{CD} 27^{+}\right)$в периферической крови значительно больше, чем у небеременных и у женщин с привычным невынашиванием беременности (ПНБ). $\mathrm{CD} 19^{+} \mathrm{CD} 24^{\text {high }} \mathrm{CD} 27^{+}$-Врег, выделенные из периферической крови женщин в I триместре беременности, способны ингибировать секрецию ФНО $\alpha$ активированными Т-клетками ex vivo [61, 62]. В-клетки небеременных женщин, культивируемые с сывороткой женщин с физиологической беременностью, продуцируют более высокий уровень ИЛ-10, чем эти же клетки при культивировании с сывороткой пациенток с ПНБ или аутологичной сывороткой. Следовательно, Врег играют важную роль в течение гестации, подавляя нежелательный ответ материнских Т-клеток на аллоантигены отцовского происхождения, и таким образом участвуют в становлении толерантности. 
В экспериментальной модели полуаллогенной беременности у мышей показано изменение фенотипа и функции В-клеток в маточном микроокружении во время гестации. Значительное повышение частоты В-клеток было обнаружено в периимплантационном периоде между 2,5 и 8,5 ДГ. Также выявлено повышение экспрессии костимуляторных молекул CD80, CD86 и маркера активации CD27 на этих клетках и их способность значительно подавлять пролиферацию и ак-

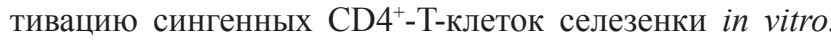
Способность В-клеток в маточном микроокружении беременных мышей подавлять Т-клеточный пролиферативный ответ и активацию эффекторных Т-лимфоцитов коррелирует со значительным повышением доли ИЛ-10продуцирующих клеток в популяции маточных В-клеток $[63,64]$. Экспрессия Врег-ассоциированных маркеров TLR9 и CD86, детектированная на B-клетках селезенки, на 3-й ДГ была выше, а экспрессия TLR2 - ниже у самок $\mathrm{CBA} / \mathrm{J}$, оплодотворенных самцами DBA/2/J, предрасположенных к спонтанным абортам (CA), чем у мышей с нормально развивающейся беременностью $(\mathrm{CBA} / \mathrm{J} \times$ $\mathrm{BALB} / \mathrm{c})$. На 14-й ДГ у CBA/J × DBA/2J наблюдали более низкий уровень экспрессии TLR4 и CD80 и более высокий - CD86 по сравнению с физиологической беременностью. Дифференциальная экспрессия TLRs и костимуляторных молекул на В-клетках селезенки самок мышей с СА и самок с нормально протекающей беременностью предполагает вовлечение этих клеток в регуляцию периферического иммунного ответа у беременных самок мышей, предрасположенных к СА [65].

В исследованиях, посвященных изучению различных подклассов В-клеток, показано, что Врег с фенотипом MZB способствуют поддержанию беременности. Эти клетки представлены в селезенке беременных самок в норме, но отсутствуют у мышей с осложненной беременностью. MZB-клетки дифференцируются в плазматические клетки с коротким жизненным циклом и вырабатывают низкоаффинные, в основном естественные, IgM- и IgA-антитела, которые контролируют 1-ю волну инфекции и переключают иммунный ответ c Th1-зависимого на Th2-зависимый [66]. МZB-клетки, активированные через TLRs, модулируют опосредуемый Т-клетками воспалительный ответ через продукцию ИЛ-10 [67].

Оценке роли ИЛ-10-продуцирующих В-клеток в акушерской патологии посвящены работы, в которых нарушение продукции ИЛ-10 рассматривается как один из ключевых механизмов ПНБ. У женщин, страдающих ПНБ, значительно снижены уровни мРНК и белка ИЛ-10, секретируемого при рестимуляции ex vivo, а также количество CD19+-B-клеток и уровень ИЛ-10 в периферической крови относительно пациенток с нормально протекающей беременностью. Выявлена отрицательная корреляция между долей CD19+-клеток, общим количеством $\operatorname{IgG}$ в сыворотке и частотой абортов, что может свидетельствовать о вкладе ИЛ-10-продуцирующих В-клеток в подавление продукции аутоантител и успешное течение беременности $[22,68]$.
В исследовании С.Y. Yuе и соавт. было установлено, что на всех сроках беременности уровень ИЛ-35 в сыворотке крови превышал те же показатели у небеременных женщин, а у пациенток с ПНБ сывороточная концентрация ИЛ-35 была значимо меньше, чем у женщин с успешным развитием беременности. Это может свидетельствовать о связи ИЛ-35 с установлением и поддержанием материнской толерантности к полуаллогенному плоду, а дефицит этого цитокина является одним из патогенетических механизмов СА [69]. Клинические данные совпадают с результатами экспериментальной paботы A. Slavek и соавт., показавшими снижение частоты В-клеток, продуцирующих ИЛ-35 на 3-й ДГ, как на локальном, так и на периферическом уровнях у самок мышей с СА [70]. Это дает основания предполагать участие ИЛ-35-продуцирующих Врег в поддержании беременности.

Таким образом, Врег вносят важный вклад в развитие беременности, контролируя микроокружение эмбриона через индукцию и поддержание Трег, модификацию ответа Т-хелперов и ингибирование ответа эффекторных клеток, включая цитотоксические Т-клетки, НК-клетки и ДК.

\section{Заключение}

В настоящее время получены многочисленные доказательства участия В-клеток в негативной регуляции иммунного ответа. Среди множества субпопуляций Врег выявлен малочисленный, но обладающий мощной супрессорной активностью подкласс В-клеток, способный ингибировать иммунный ответ через продукцию противовоспалительного цитокина ИЛ-10, а также по ИЛ-10-независимым механизмам через секрецию ИЛ-35 и ТФР $\beta$. Кроме того, супрессорная функция ИЛ-10-продуцирующих клеток (В10-клетки) может осуществляться с участием межклеточных взаимодействий. Так как уникальная для В10-клеток комбинация фенотипических маркеров не выявлена, они могут быть идентифицированы по продукции ИЛ-10 после соответствующей кратковременной стимуляции ex vivo. Врег ингибируют дифференцировку воспалительных Th1-, Th17- и НКТ-клеток и индуцируют дифференцировку Трег, а также участвуют в поддержании иммунной толерантности. В ряде исследований подтверждена важная роль В-клеток в регуляции иммунного ответа в течение беременности. Врег являются мощными продуцентами противовоспалительного цитокина ИЛ-10, необходимого для благополучного исхода беременности, а его дефицит может приводить к задержке роста и даже к гибели плода. Хотя с клинической точки зрения роль Врег как жизненно важных участников иммунного гомеостаза общепризнана, знания в этой области остаются относительно новыми и нуждаются в продолжении инновационных клинических исследований. Важно получить ответ на вопросы о взаимодействии Врег с другими иммунными клетками, которое необходимо для обеспечения материнской иммунной толерантности, а также продолжить исследования событий, связанных 
с неоптимальной имплантацией - критической фазой беременности с высоким уровнем иммунорегуляции, которая лежит в основе многих патологий беременности. Необходимо точно определить, как транскрипция гена ILIO в В-клетках и иммунная супрессия регулируются на молекулярном уровне. Предстоит окончательно продемонстрировать, является ли подавление иммунитета В10-клетками сайт-специфическим или генерализованным. В последние 10 лет клинические испытания с исследованием Врег сосредоточены главным образом на определении потенциала этих клеток в качестве прогностических или диагностических маркеров. Использование прогрессивных методов генной инженерии и генетического репрограммирования позволяет надеяться на значительный прогресс в развитии новых медицинских технологий в области патологии репродукции.

Вклад авторов. Написание текста - Богданова И.М.; сбор и анализ литературы - Богданова И.М., Артемьева К.А.; анализ литературы и редактирование текста - Болтовская М.Н.

\section{- Литература/References}

1. Harris D.P., Haynes L., Sayles P.C., Duso D.K., Eaton S.M., Lepak N.M., Johnson L.L., Swain S.L., Lund F.E. Reciprocal regulation of polarized cytokine production by effector B and T cells. Nat. Immunol. 2000; 1 (6): 475-82. DOI: https://doi.org/10.1038/82717

2. Mauri C. Regulation of immunity and autoimmunity by B cells. Curr. Opin. Immunol. 2010; 22 (6): 761-7. DOI: https://doi. org/10.1015/j.coi. 10.009

3. Лушова А.А., Жеремян Э.А., Астахова Е.А., Спиридонова А.Б., Бязрова М.Г., Филатов А.В. Субпопуляции В-лимфоцитов: функции и молекулярные маркеры. Иммунология. 2019; 40 (6): 63-76. DOI: https://doi.org/10.24411/0206-4952-201916009 [Lushova A.A., Zheremyan E.A., Astakhova E.A., Spiridonova A.B., Byazrova M.G., Filatov A.V. B-lymphocyte subsets: functions and molecular markers. Immunologiya. 2019; 40 (6): 63-76. DOI: https://doi.org/10.24411/0206-4952-2019-16009 (in Russian)]

4. Martin F., Chan A.C. Pathogenic roles of B cells in human immunity; insight from the clinic. Immunity. 2004; 20 (5): 517-27. DOI: https://doi.org/10.1016/s1074-76113(04)00112-8

5. Mizoguchi E., Mizoguchi A., Preffer F.I., Bhan A.K. Regulatory role of mature B cells in a murine model of inflammatory bowel disease. Int. Immunol. 2000; 12 (5): 597-605. DOI: https://doi. org/10.1093/intimm/12.5.597

6. Fillatreau S., Swenle C.H., McGeachy M.J., Gray D., Anderton S.M. B cell regulate autoimmunity by provision of IL-10. Nat. Immunol. 2002; 3 (10): 944-50. DOI: https://doi.org/10.1038/ni833

7. Mauri C., Menon M. The expanding family of regulatory B cells. Int. Immunol. 2015; 27 (10): 479-86. DOI: https://doi. org/10.1093/intimm/dxv038

8. Колесникова Н.В., Самойленко Е.С. Роль цитокинов в патогенезе инфекционного эндокардита. Иммунология. 2020; 41 (3): 262-8. DOI: https://doi.org/10.33029/0206-4952-2020-41-3-262-268 [Kolesnikova N.V., Samoylenko E.S. The role of cytokines in the pathogenesis of infective endocarditis. Immunologiya. 2020; 41 (3): 262-8. DOI: https://doi.org/10.33029/0206-4952-2020-41-3-262-268 (in Russian)]

9. Validzadeh A., Sanaei R., Rezaei N., Azizi G., Fekrvand S., Aghamohammadi A., Yazdani R. Potential role of regulatory B cells in immunological diseases. Immunol. Lett. 2019; 215: 48-59. DOI https://doi.org/10.1016/j.imlet.2019.08.004

10. Mauri C., Bosma A. Immune regulatory function of B cells. Annu. Rev. Immunol. 2012; 30: 221-41. DOI: https://doi.org/10.1146/ annurev-immunol-020711-074934

11. Katz S.I., Parker D., Turk J.L. B cell suppression of delayed hypersensitivity reaction. Nature. 1974; 251 (5475): 550-1. DOI: https://doi.org/10.1038/251550a0

12. Neta R., Salvin S.B. Specific suppression of delayed hypersensitivity: the possible presence of a suppressor B cell in regulation of delayed hypersensitivity. J. Immunol. 1974; 113 (6): 1716-25.

13. Vadasz H.T. Kessel A., Toubi E. B-regulatory cells in autoimmunity and immune mediated inflammation. FEBS Lett. 2013; 587 (13): 2074-8. DOI: https://doi.org/10.1016/febslet. 2013.05.023

14. Wolf S.D., Dittel B.N., Hardardottir F., Janeway C.A. Experimental autoimmune encephalitis induction in genetically d-cell deficient mice. J. Exp. Med.1996; 184 (6): 2271-8. DOI: https://doi. org/10.1084/jem.184.6.2271

15. Mizoguchi A., Mizoguchi E., Takedatsu H., Blumderg R.S., Bhan A.K. Chronic intestinal inflammatory condition generates IL-10producing regulatory $\mathrm{B}$ cell subset characterized by $\mathrm{Cd} 1 \mathrm{~d}$ upregula- tion. Immunity. 2002; 16 (2): 219-30. DOI: https://doi.org/10.1016/ s1074-7613(02)00274-1

16. Mauri C., Gray D., Mishtag N., Londel M. Prevention of arthritis by interleukin 10-producing B cells. J. Exp. Med. 2003; 197 (4): 489-501. DOI: https://doi.org/10.1084/jem20021293

17. Bouaziz J.D., Yanaba K., Tedder T.F. Regulatory B cell as inhibitors of immune responses and inflammation. Immunol. Rev. 2008; 224: 201-14. DOI: https://doi.org/10.1111/j.1600- 065X.2008.00661x

18. Busse M., Campe K.J., Nowak D., Schumacher A., Plenagl S., Langwisch S., Tiegs G., Reinhold A., Zenclussen A.C. IL-10 producing B cell rescue mouse fetuses from inflammation-driven fetal death and are able to modulate T cell immune responses. Sci. Rep. 2019; 9 (1): 9335. DOI: https://doi.org/10.1038/s41598-019-45860-2

19. Jensen F., Muzzio D., Soldati R., Fest S., Zenclussen A.C Regulatory B10 cells restore pregnancy tolerance in a mouse model Biol. Reprod. 2013; 89 (4): 90. DOI: https://doi.org/10.1095/biolreprod.113.110791

20. Ghaebi M., Nouri M., Ghasemzadeh A., Farzadi L., Jadidi-Niaragh F., Ahmadi M., Yousefi M. Immune regulatory network in successful pregnancy and reproductive failures. Biomed. Pharmacother 2017; 88: 61-73. DOI: https://doi.org/10.1016/biopha 2017.01.016

21. Sung N., Byeon H.J., Garcia M.D.S., Skariah A., Wu L., Dambaeva S., Beaman K., Gilman-Sachs A., Kwak-Kim J. Deficiency in memory B cell compartment in a patient with infertility and recurrent pregnancy losses. J. Reprod. Immunol. 2016; 118: 70-5. DOI: https:// doi.org/10.1016/j.jri.2016.09.003

22. Koushaeian L., Ghorbani F., Ahmadi M., Eghbal-Fard S., Zamani M., Danaii S., Yousefi B., Jadidi-Niaragh F., Hamdi K., Yousefi $\mathrm{M}$. The role of IL-10 producing B cell in repeated implantation failure patients with cellular immune abnormalities. Immunol. Lett. 2019; 214: 16-22. DOI: https://doi.org/10.1016/j.imlet.2019.08.002

23. Abebe E.C., Dejenie T.A., Ayele T.M., Baye N.D., Teshome A.A., Miche Z.T. The role of regulatory B cells in health and disease: a systemic review. J. Inflamm. Res. 2021; 14: 75-84. DOI: https://doi.org/10.2147/JIR.S286426

24. Iwata Y., Matsushita T., Horikawa M., Dilillo D.J., Yanaba K., Venturi G.M., Szabolcs P.M., Bernstein S.H., Magro C.M., Williams A.D., Hall R.P., St Clair W.E., Tedder T.F. Characterization of a rare IL-10-competent B cell subset in human that parallels mouse regulatory B10 cells. Blood. 2011; 117 (2): 530-41. DOI: https://doi. org/10.1182/blood-2010-07-294249

25. Yanaba K., Bouaziz J.D., Haas K.M., Poe J.C., Fujmoto M., Tedder T.F. A regulatory B cell subset with a unique CD1dhiCD5 phenotype controls T-cell-dependent inflammatory responses. Immunity. 2008; 28 (5): 639-50. DOI: https://doi.org/10.1016/j. $\mathrm{immu} / 2008.03 .017$

26. Rosser E.C., Mauri C. Regulatory B cells: origin, phenotype and function. Immunity. 2015; 42 (4): 607-12. DOI: https://doi. org/10.1016/jimmuni.2015.04.005

27. Mauri C., Menon M. Human regulatory B cells in health and disease: therapeutic potential. J. Clin. Invest. 2017; 127 (3): 772-9. DOI: https://doi.org/10. 1172/jci85113

28. Banko Z., Pozsgay J., Szili D., Toth M., Gati T., Nagy G., Rojkovich B., Sármay G.I Induction and differentiation of IL-10- producing regulatory $\mathrm{B}$ cells from healthy blood donors and rheumatoid arthritis patients. J. Immunol. 2017; 198 (4): 1512-20. DOI: https:// doi.org/10.4049/jimmunol.1600218 
29. Lykken J.M., Candando K.M., Tedder T.F. Regulatory B10 cell development and function. Int. Immunol. 2015; 27 (10): 471-7. DOI: https://doi.org/10. 1093/intimm/dxv046

30. Ding T., Yan F., Cao S., Ren X. Regulatory B cells: new member of immunosuppressive cell club. Hum. Immunol. 2015; 76 (9): 615-21. DOI: https://doi.org/10.1016/humim.2015.09.006

31. Pestka S., Krause C.D., Sarkar D., Walter M.R., Shi Y, Fisher P.B. Interleukin-10 and related cytokines and receptors. Annu. Rev. Immunol. 2004; 22: 929-79. DOI: https://doi.org/10.1146//annurev.immunol.22.012703.104622

32. Flores-Borja F., Bosma A., Ng D., Reddy V., Ehrenstein M., Isenborg D.A., Mauri C. CD19+CD24hicd38hi B cells maintain regulatory T cells white limiting TH1 and TT17 differentiation. Sci. Transl. Med. 2013; 5 (173): 173ra23. DOI: https://doi.org/10.1126/scitranslmed.3005407

33. Ray A., Wang I., Dittel B.N. IL-10-independent regulatory B cell subsets and mechanisms of action. Int. Immunol. 2015; 27 (10): 531-6. DOI: https://doi.org/10.1093/intimm/dxv033

34. Tian J., Zekzer D., Hanssen L., Lu Y., Olcott A., Kaufman D.L. Lypopolysaccharide-activated B cells down-regulate Th1 immunity and prevent autoimmune diabetes in nonobese diabetic mice. J. Immunol. 2001; 167 (2): 1081-89. DOI: https://doi.org/10.4049/ jimmunol.167.2.1081

35. Parekh V.V., Prasad D.V., Banerjee P.P., Joshi B.N., Kumar A., Mishra G.C. B cell activated lypopolysaccharide, but not by anti-Ig and anti-CD40 antibody induce anergy in $\mathrm{CD}^{+} \mathrm{T}$ cells: role of TGRFbeta 1. J. Immunol. 2003; 170 (12): 5897-911. DOI: https://doi org/10.4049/jimmunlol.170.12.5897

36. Ran Z., Yue-Bei L., Qui-Ming Z., Huan Y. Regulatory B cells and its role in central nervous system inflammatory demyelinating disease. Front. Immunol. 2020; 11: 1884. DOI: https://doi.org/10.3389 fimmu.2020.01884

37. Xue J.M., Ma F., An Y.F., Suo L.M., Geng X.R., Song Y.N., Mo L.H., Luo X.Q., Zhang X.W., Liu D.B., Zhao C.Q., Yang P.C. Probiotic extracts ameliorate nasal allergy by inducing interleukin-35producing dendritic cells in mice. Int. Forum Allergy Rhinol. 2019; 9 (11): 1289-96. DOI: https://doi.org/10.1002/alr.22438

38. Shen P., Roch T., Lampropoulou V., O'Connor R.A., Stervbo U., Hilgenberg E., Ries S., Dang V.D., Jaimes Y., Daridon C., Li R., Jouneau L., Boudinot P., Wilantri S., Sakwa I., Miyazaki Y., Leech M.D., McPherson R.C., Wirtz S., Neurath M., Hoehlig K., Meinl E., Grützkau A., Grün J.R., Horn K., Kühl A.A., Dörner T., Bar-Or A., Kaufmann S.H.E., Anderton S.M., Fillatreau S. IL-35-producing $\mathrm{B}$ cell are critical regulators of immunity during autoimmune and infectious disease. Nature. 2014; 507 (7492): 366-70. DOI: https:// doi.org/10.1038/nature12979/

39. Hilgenberg E., Shen P., Dang V.D., Ries S., Sakwa I., Fillatreau S. Interleukin-10-producing B cells and the regulation of immunity. Curr. Top. Microbiol. Immunol. 2014; 380: 69-92. DOI: https://doi.org/10.1007/978-3-662-43492-5 4

40. Choi J.K., Egwuagu C.E. Interleurin 35 regulatory B cells. J. Mol. Biol. 2021; 433 (1): 166607. DOI: https://doi.org/10.1016/j. jimb.2020.07.019

41. Yoshizaki A., Miyogaki T., DiLillo D.J., Matsushita T., Horikawa M., Kountikov E., Spolski R., Poe J.C., Leonard W.J., Tedder T.F. Regulatory B cells control T cell autoimmunity through IL-21-dependent cognate interactions. Nature. 2012; 491 (7423): 264 8. DOI: https://doi.org/10.1038/nature. 11501

42. Bermejo D.A., Jackson S.W., Gorosito-Serran M., Acosta-Rodrogues E.V., Amezcua-Vesely M.C., Sather B.D., Singh A.K., Khim S., Mucci J., Liggitt D., Campetella O., Oukka M., Gruppi A., Rawlings D.J. Trypanosoma cruzi trans-sialidase initiates a program independent of the transcription factors ROR $\gamma \mathrm{t}$ and Ahr that leads to IL-17 production by activated B cells. Nat. Immunol. 2013; 14 (5): 514-22. DOI: https:// doi.org/10.1038/ni.2569

43. Lindner S., DahlkeK., Sonthtimer K., Hagn M., Kaltenmeier C., Barth T.F.E., Beyer T., Reister F., Fabricius D., Lotfi R., Lunov O., Nienhaus G.U., Simmet T., Kreienberg R., Möller P., Schrezenmeier H., Jahrsdörfer B. Interleukin 21-induced granzyme B-expressing B cells infiltrate tumors and regulate T cells. Cancer Res. 2013; 73 (8): 2468 79. DOI: https://doi.org/10.1158/0008-5472.CAN-12-3450

44. Bodhankar S., Galipeau D., Vandenbark A.A., Offner H. PD-1 interaction with PD-L1 but not PD-L2 on B cells mediates protective effects of estrogen against EAE. J. Clin. Cell. Immunol. 2013; 4 (3): 143. DOI: https://doi.org/10.4172/2155-9899.1000143

45. Lopez-Medina M., Carillo-Martin I., Leyva-Rangel J., Alpudche-Aranda C., Ortiz-Navarrete V. Salmonella impairs CD8 T cell response through PD-1:PD-L axis. Immunobiology. 2015; 220 (12) 1369-80. DOI: https://doi.org/10.1016/j.imbio.2015.07.005

46. Lundy S.K., Fox D.A. Reduced Fas ligand-expressing splenic CD5+ B-lymphocytes in severe collagen-induced arthritis. Arthritis Res. Ther. 2009; 11 (4): R128. DOI: https://doi.org/10.1186/ar2795

47. Mizoguchi A., Bhan A.K. A case for regulatory B cells. J. Immunol. 2006; 176 (2): 705-10. DOI: https://doi.org/10.4049/jimmunol.176.2.705

48. Yanaba K., Bouaziz J.-D., Matsushita T., Tsubata T., Tedder T.F The development and function of regulatory B cells expressing IL-10 (B10 cells) requires antigen receptor diversity and TLR signals. J. Immunol. 2009; 182 (12): 7454-72. DOI: https://doi.org/10.4049/jimmunol.0900270

49. Filatreau S., Manfroi B., Dorner T. Toll-like receptor signaling in B cells during systemic lupus erythematosus. Nat. Rev. Rheumatol. 2021; 17 (2): 98-108. DOI: https://doi.org/10.1038/s41584$020-00544-4$

50. Baba Y., Matsumoto M., Kurosaki T. Signals controlling the development and activity of regulatory B-lineage cells. Int. Immunol. 2015; 27 (10): 487-93. DOI: https://doi.org/10.1093/intimm/dxv027

51. Candando K.M., Lykken J.M., Tedder T.F. B10 cell regulation of health and disease. Immunol. Rev. 2014; 259 (1): 259-72. DOI: https://doi.org/10.1111/imr.12176

52. Kimura S., Rickert C., Kojima L., Aburawi M., Tanimine N Fontan F., Deng K., Tector H., Lee K.M., Yeh H., Markmann J.F. Regulatory $\mathrm{B}$ cells require antigen recognition for effective allograft tolerance induction. Am. J. Transplant. 2020; 20 (4): 977-87. DOI: https:// doi.org/10.1111/ajt.15739

53. Maseda D., Smith S.H., DiLillo D.J., Bryant J.M., Candando K.M., Weaver C.T., Tedder T.F. Regulatory B10 cells differentiate into antibody-secreting cells after transient IL-10 production in vivo J. Immunol. 2012; 188 (3): 1036-48. DOI: https://doi.org/10.4049/ jimmunol.1102500

54. Arck P.C., Hecher K., Fetomaternal immune cross-talk and its consequences for maternal and offspring's health. Nat. Med. 2013; 19 (5): 548-56. DOI: https://doi.org/10.1038/nm.3160

55. Abu-Raya E., Michalski C., Sadarangani M., Lavoie P.M. Maternal immunological adaptation during normal pregnancy. Front Immunol. 2020; 11: 575197. DOI: https://doi.org/10.3389/fimmu.2020.575197

56. Guzman-Genuino R.M., Diener K.R. Regulatory B cells in pregnancy: lessons from autoimmunity, graft tolerance, and cancer Front. Immunol. 2017; 8: 172. DOI: https://doi.org/10.3389/fimmu.2017.00172

57. Dutta S., Sengupta P. Defining pregnancy phases with cytokine shift. J. Pregnancy Reprod. 2017; 1 (4): 1-3. DOI: https://doi org/10.15761/JPR.1000124

58. Huang N., Chi Y., Qiao J. Role of regulatory T cells in regulating fetal-maternal immune tolerance in healthy pregnancies and reproductive disease. Front. Immunol. 2020; 11: 1023. DOI: https://doi. org/10.3389/fimmu. 2020.01023

59. Robertson S.A., Care A.S., Skinner R.J. Interleukin 10 regulates inflammatory cytokine synthesis to protect against lypopolysaccaride-induced abortion and fetal growth restriction in mice. Biol Reprod. 2007; 76 (5): 738-48. DOI: https://doi.org/10.1095/biolreprod.106.056143

60. Robertson S.A., Skinner R.J., Care A.S. Essential role for IL-10 in resistance to lypopolisaccharide-induced preterm labor in mice. J. Immunol. 2006; 177 (7): 488-96. DOI: https://doi.org/10.4049/ jimmunol.177.7.4888

61. Rolle L., Memarzadeh Tehran M., Morell-Garcia A. Cutting edge: IL-10 producing regulatory B cells in early human pregnancy Am. J. Reprod. Immunol. 2013; 70 (6): 448-53. DOI: https://doi. org/10.1111/aji.1215

62. Fettke F., Schumacher A., Costa S-D., Zenclussen A.C. B cells the old new players in reproductive immunology. Front. Immunol 2014; 23 (5): 285. DOI: https://doi.org/10.3389/fimmu.2014.00285

63. Gusman-Genuino R.M., Eldi P., Garcia-Valtanen P., Hayball J.D., Diener K.R. Uterine B cells exhibit regulatory properties during the peri-implantation stage of murine pregnancy. Front. Immunol. 2019; 10: 2899. DOI: https://doi.org/10.3389/fimmu.2o19.02899

64. Guzman-Genuino R.M., Hayball J.D., Diener K.R. Regulatory B cells: dark horse in pregnancy immunotherapy? J. Mol. Biol. 2020; 433 (1): 166596. DOI: https://doi.org/10.1016/j.jmb.2020.07.008

65. Lorek D., Kedzierska A.E., Slawek A., Chelmonska-Soyta A. Expression of Toll-like receptors and costimulatory molecules in splenic $\mathrm{B}$ cell in normal and abortion prone murine pregnancy 
model. Am. J. Reprod. Immunol. 2019; 82 (2): e13148. DOI: https:// doi.org/10.1111/aji.13148

66. Dutta S., Sengupta P. Functions of follicular and marginal zone B cells in pregnancy. Asian Pac. J. Reprod. 2018; 7(4): 191-2. DOI: https://doi.org/10.4103/2305-0500.237058

67. Lenert P., Brummel R., Field E.H., Ashman R. TLR-9 activation of marginal zone B cells in lupus mice regulates immunity through increased IL-10 production. J. Clin. Immunol. 2005; 25 (1): 29-40. DOI: https://doi.org/10.1007/s10875-005-0355-6

68. Danaii S., Ghorbati F., Ahmadi M., Abbaszadeh H., Koushaeian L., Soltani-Zangbar M.S., Mehdizadeh A., Hojjat-Farsangi M., Kafil H.S., Aghebati-Maleki L., Yousefi M. IL-10-producing B cells

\section{Сведения об авторах}

Богданова Ирина Марковна - канд. биол. наук, ст. науч. сотр лаборатории патологии репродукции ФГБНУ НИИМЧ им. ак. А.П. Авцына Минобрнауки России, Москва, Российская Федерация

E-mail:malaj43@mail.ru

http://orcid.org/0000-0002-6529-8149

Артемьева Ксения Александровна - канд. мед. наук, науч. сотр. лаборатории патологии репродукции ФГБНУ НИИМЧ им. ак. А.П. Авцына Минобрнауки России, Москва, Российская Федерация

E-mail: artemjeva ksenia@mail.ru

http://orcid.org/0000-0002-1014-752X

Болтовская Марина Николаевна - д-р биол. наук, проф., зав лабораторией патологии репродукции ФГБНУ НИИМЧ им. ак. А.П. Авцына Минобрнауки России, Москва, Российская Федерация

E-mail: maribolt@mail.ru

http://orcid.org/0000-0002-9751-2066 play important role in the pathogenesis of recurrent pregnancy loss. Int Immunopharmacol. 2020; 87: 106806. DOI: https://doi.org/10.1016/j. intimp. 2020.106806

69. Yue C.Y., Zhang B., Ying C.M. Elevated serum level of IL-35 associated with the maintenance of maternal-fetal immune tolerance in normal pregnancy. PLoS One. 2015; 10 (6): e0128219. DOI: https:// doi.org/10.1371/journal.pone.0128219

70. Slavek A., Lorek D., Kedzierska A.E., Chelmonska-Soyta A. Regulatory B cells with IL-35 IL-10 expression in a normal and abortion-prone murine pregnancy model. Am. J. Reprod. Immunol. 2020; 83 (3): e13217. DOI: https://doi.org/10.1111/aji.13217

\section{Authors' information}

Irina M. Bogdanova - PhD, Senior Researcher, Lab. of Pathology of Reproduction, A.P. Avtsyn RIHM of the MSHE of Russia, Moscow, Russian Federation

E-mail: malaj43@mail.ru

http://orcid.org/0000-0002-6529-8149

Ksenia A. Artemyeva - PhD, Researcher, Lab. of Pathology of Reproduction, A.P. Avtsyn RIHM of the MSHE of Russia, Moscow, Russian Federation

E-mail: artemjeva_ksenia@mail.ru

http://orcid.org/0000-0002-1014-752X

Marina N. Boltovskaya - Dr.Sci., Prof., Head of the Lab. of Pathology of Reproduction, A.P. Avtsyn RIHM of the MSHE of Russia, Moscow, Russian Federation

E-mail: maribolt@mail.ru

http://orcid.org/0000-0002-9751-2066 